\title{
Ciência da informação: atuação profissional e as contribuições para o desenvolvimento do campo científico por parte dos egressos do PPGCI (ICI/UFBA)
}

\author{
Aida Varela \\ Doutora em ciência da informação. Universidade de Brasília (UnB). \\ E-mail:varela@ufba.br
}

Maura Iclea Castro

Mestre em ciência da informação pela Universidade Federal da Bahia (UFBA)

E-mail: mauraiclea@gmail.com

\section{Igor Barauna Guimarães}

Graduado em letras pela Universidade Católica do Salvador (UCSAL). Graduando em jornalismo pela Faculdade da Cidade do Salvador (FCS). Bolsista de Iniciação Científica da Universidade Federal da Bahia (UFBA), no período 2008-2009.

E-mail: igor.guimaraes@hotmail.com

\section{Resumo}

Diante do conflito do mundo do trabalho provocado pelas mudanças tecnológicas em que fronteiras profissionais desaparecem, acredita-se ser de fundamental importância pesquisas subsidiem o

desenvolvimento de novas trajetórias da formação e as demandas de contexto. Relata-se uma investigação sobre a atuação profissional e a contribuição de egressos da pós-graduação do Instituto de Ciência da Informação (UFBA-POSICI) para o campo científico da área, que defenderam suas dissertações no período de 1998-2006, apresentando indicadores que permitiram analisar tendências sobre o desempenho dos cursos, dos próprios titulados e do seu mercado profissional. Percebeuse, por meio dos dados coletados e analisados, que diferentes questões puderam ser visualizadas no tocante à atuação profissional, à contribuição do campo científico da $\mathrm{Cl}$ e à importância dos cursos de pós-graduação para os processos de inovação do conhecimento da sociedade.

\section{Palavras-chave}

Ciência da informação. Egressos. Pós-graduação. Atuação profissional.

Information science: professional performance and contributions for the development of the scientific field by the graduates from PPGCI (ICI/ UFBA)

\begin{abstract}
Taking into consideration the different conflicts in the labor world as a result of the technological changes where professional frontiers fade away, it is of fundamental importance that research may subsidize the development of new trajectories of education and context demands. A research has been carried out about the professional performance of graduates from Post-Graduation of the Institute of Information Science for the scientific field in this area. Dissertations presented by them from 1998 to 2006 show indicators which allow an analysis of the trends about the performance of the students, the courses and their professional market. Through data collected and analyzed, different issues can be visualized with reference to professional performance, contribution to the scientific field of Information Science, as well as to the importance of the Post-Graduation courses for the processes of innovating society knowledge.

\section{Keywords}

Information science. Graduates. Post-Graduation. Professional performance.

\section{INTRODUÇÃO}

O sistema das profissões e suas articulações passam, nesse momento, por uma reorganização de seus componentes, permitindo a criação de serviços e profissões, ao tempo em que enfraquecem outras. No entender de Cronin (1998), novas situações trazem consigo o fenômeno de desestruturação e, por sua vez, o processo de integração a uma nova tecnologia desestabiliza o funcionamento da atividade econômica e faz com que seja necessária uma adaptação das estruturas e dos comportamentos.

Para Abbott (1988), as profissões são integrantes de um mesmo sistema, no qual há competição por espaço e poder, cuja característica é a interdependência, embora cada profissão controle seu espaço de trabalho ou jurisdição. As profissões estão em permanente disputa por um espaço, e o sucesso delas depende do esforço e da capacidade de competir com outras profissões dentro de um sistema.

Para Bourdieu (2006, p.148-149), “o título profissional é um capital simbólico institucionalizado, legal. [...]”. "É a raridade simbólica do título no espaço dos nomes de profissões que tende a comandar a retribuição da profissão". É o valor institucionalizado do título que serve de instrumento para que se defenda e se mantenha o valor do trabalho. Quem detém os mesmos títulos tende a constituir-se em grupos e dotar-se de organismos permanentes, como associações, sindicatos, entre outros, que se destinam a assegurar a coesão do grupo e defender e promover interesses materiais e simbólicos.

Ao estudar as profissões, uma das dificuldades reside em lidar com conceitos sobre os quais, algumas vezes, não existe consenso entre os especialistas. Nesse sentido, segundo Freidson (1998), que estabeleceu alguns parâmetros (especificidade histórica e geográfica, organização do trabalho humano e o papel do Estado para o desenvolvimento do profissionalismo), a unanimidade do uso de conceitos para nortear a análise das profissões é mais aparente do que real. Mesmo assim, os conceitos cobrem as noções de monopólio de conhecimentos, de autonomia e de prestação de serviços. 
fato de prestar serviços pressupõe uma competência além de conhecimentos específicos adquiridos no decorrer da formação. Esta formação é um corpo sistemático de teorias (DUBAR, 2005) que permite a aquisição de uma cultura profissional, encarando o ideal de serviço fundamentado em competências específicas.

Segundo Cunha (2006), as mudanças ocorridas com a revolução tecnológica ocasionam alguns conflitos no mundo do trabalho, em que fronteiras profissionais desaparecem, parcerias surgem, outras se transformam e novas demarcações ocupacionais ou jurisdições surgem. Com isso, as organizações tendem a modificar a arquitetura organizacional, necessitando de profissionais com competências diferenciadas. Isso demanda modificações urgentes nas práticas educacionais para formar um novo profissional que atenda à demanda dessa nova organização.

Para Mueller (2004, p.92), a formação de profissionais da informação comporta dois eixos. No eixo horizontal, há um conjunto de fazeres ligados a ambiências, como e nele se situam, no imaginário social, as profissões de arquivistas e bibliotecários. Tais ambiências encontram um eixo vertical em que há um conjunto de processos que atuariam em dois níveis: o da dimensão do documento materialmente considerado e o da informação "como conjunto de estruturas simbolicamente significantes com a competência de graus de conhecimento para o indivíduo e para o seu meio" (SMIT; BARRETO, 2002, p.18, apud BAPTISTA; MUELLER, 2004, p.92). Permeando tais eixos está a ciência da informação (CI) fornecendo o esboço teóricometodológico, objeto específico de estudo da pósgraduação.

Privilegiou-se, na presente pesquisa, o estudo daqueles que realizaram o curso de pós-graduação stricto sensu. Dessa forma, a pesquisa investigou qual a contribuição dos mestres formados pelo Programa de Pós-graduação em Ciência da Informação da Universidade Federal da Bahia (PPGCI/UFBA) no tocante ao desenvolvimento do campo científico da área da ciência da informação e, ainda, como tem se dado a atuação profissional desses sujeitos, em face do curso realizado.

\section{ESPAÇO, TEMPO E REFLEXÕES SOBRE OS DESAFIOS DA PÓS-GRADUACุÃO}

A educação é considerada como um dos pilares da sociedade. Cada vez mais as pessoas procuram ampliar a sua formação educacional, visando a obter melhores colocações no mercado de trabalho, ou mesmo compreender as questões que perpassam a relação homem/mundo. Esta busca vem se tornando concorrida, em um momento histórico em que se considera a informação e o conhecimento como base para a igualdade social. Diante destas questões, acredita-se ser de fundamental importância pesquisas que contribuam para o entendimento da trajetória daqueles que, em um determinado momento, procuraram uma formação educacional para colocá-los em consonância com a demanda do contexto social.

Com isso, o desenvolvimento da educação continuada tem sido muito recorrente entre aqueles que desejam ultrapassar os limites da competitividade. Figueiredo e Lima (apud MIRANDA; SOLINO, 2006) consideram a educação continuada como aperfeiçoamento integral em que há transferência de conhecimentos e práticos de usos e costumes e está relacionada com valores, atitudes e motivação. Com a educação continuada, o indivíduo fica apto a praticar melhor o que ele conhece.

Em 1994, Lancaster destacou a importância dos programas de educação continuada e de pós-graduação para os profissionais da informação como alternativa para: a) qualificação de especialistas em acesso à informação capazes de implementar e administrar impactos tecnológicos; b) capacitação de profissionais aptos a exercer funções de consultoria e administração de projetos de serviços de informação; c) formação de pesquisadores aptos a realizar estudos sobre questões da informação; d) habilitação de profissionais no entendimento das tecnologias da informação, sua implementação e condições adequadas de aplicação.

Neste sentido, cabe à universidade, sobretudo à pósgraduação, pensar sobre ensinar o que para quem e, ainda, ensinar com vistas a que, cumprindo a sua função de formar cientistas/pesquisadores aptos ao desenvolvimento da ciência. Refletir sobre a pós-graduação e sobre os sujeitos formados é de suma importância para a universidade.

No Brasil, os cursos de pós-graduação já vinham se instalando desde a década de 1930. Entretanto, somente em 1965 é que surgem no campo da legislação as primeiras regulamentações sobre a pós-graduação. A primeira lei foi a n. ${ }^{\circ} 4881-\mathrm{A}$ - a de 06 de dezembro de 1965, que versava sobre o Estatuto do Magistério Superior, que dizia que o Conselho Federal de Educação conceituaria os cursos de pós-graduação. Pouco antes havia sido aprovado o Parecer 977/65, de 03 de dezembro de 1965 , primeiro documento a regulamentar de fato a pós-graduação no país até os dias atuais. 
A pós-graduação no Brasil vem a cada dia ganhando mais espaço. Na década de 1990 inclusive, houve grande abrangência e diversificação de cursos em diversas áreas do conhecimento.

No ano 2000, os estudantes vinculados aos programas de mestrado e doutorado no país estavam chegando na casa dos 80 mil, com mais de 15 mil titulados no ano (VELLOSO, 2005, p. 35).

A proliferação tem abarcado a pós-graduação como um todo, expandindo tanto os cursos lato sensu quanto os stricto sensu, apesar de esta proliferação ser de certa forma contida e controlada, já que

concebem-se os cursos de mestrado e doutorado para uma elite pensante, para a formação dos pesquisadores por excelência e, por isso, sua expansão é tratada como devendo ser contida, e sua avaliação centralizada para melhor controle (GATTI, 2001, p. 110).

\section{A ciência da informação e a pós-graduação}

Ressalte-se que a ciência da informação, ao longo de quase meio século de história, tem propiciado o surgimento de correntes das mais diferentes matrizes e estimulado discussões que vão desde o seu domínio de estatuto científico, passando pelo objeto de estudo - a informação -, atingindo problemas de terminologia e indo até suas conexões interdisciplinares.

De acordo com Saracevic, Gomes e Braga (1974), a CI tem características gerais que são partilhadas com muitos campos modernos, motivo de sua evolução e existência. Em sua natureza, ela é interdisciplinar, contudo as relações com as várias disciplinas estão mudando. Sua evolução está inexoravelmente conectada à tecnologia e, por conseqüência, impulsiona a evolução da sociedade da informação. A CI tem forte dimensão social e humana, acima e além da tecnologia. Estas características são pilares para o entendimento do passado, presente e futuro desta área do conhecimento.

A ciência da informação atinge, hoje, um ponto crítico em sua evolução. Inúmeras são as pressões que impõem um reexame de sua problemática e das soluções encontradas de forma teórica, experimental ou prática. As mesmas pressões afetam outros campos: o tecnológico, o econômico e o social, em razão da importância da informação na evolução da sociedade, o que reforça a presença de relações interdisciplinares na ciência da informação.
Existe uma variação de interpretação quanto aos atributos da informação: a) sinônimo do termo fato; b) reforço do que já se conhece; c) liberdade de escolha ao selecionar uma mensagem; d) matéria-prima da qual se extrai o conhecimento; e) aquilo que é permutado com o mundo exterior e não apenas recebido passivamente; f) efeitos no receptor; g) algo que reduz a incerteza em determinada situação (MCGARRY, 1999).

O que é marcante nos diferentes atributos da informação é o emprego metafórico de mapas e estruturas, o que a torna um termo polissêmico. Informação é um termo polissêmico que vem sofrendo, ao longo da história, tantas variações em sua acepção, que, atualmente, seu sentido está carregado de ambigüidade, sendo confundido freqüentemente com comunicação, em menor intensidade com aprendizagem e, mais recentemente, com conhecimento.

De toda forma, o destaque maior à informação data do século XX, implicando sua apropriação com fator de produção de conhecimento no cenário de uma economia estruturada com base em estoque de conhecimento, bem como sua veloz produção e comunicação disseminadas graças às tecnologias modernas.

O primeiro curso de pós-graduação em biblioteconomia ou ciência da informação a ser criado foi o do Instituto Brasileiro de Bibliografia e Documentação (IBBD), atual Instituto Brasileiro de Informação em Ciência e Tecnologia (Ibict). O curso foi criado em nível de mestrado, com o título de Mestrado em Ciência da Informação. Este curso foi responsável pela qualificação de inúmeros pesquisadores no Brasil desde então, e atualmente funciona em nível de mestrado e doutorado. O curso de doutorado do Ibict teve início em 1992. Posteriormente, ainda na mesma década, outros cursos surgiram em diferentes unidades, como Universidade Federal de Minas Gerais (UFMG), Universidade Federal da Paraíba (UFPB), Universidade de Brasília (UnB), Pontifícia Universidade Católica de Campinas (PUCCAMP) e mais tarde os da Universidade de São Paulo (USP), Universidade Federal da Bahia (UFBA), Universidade Estadual Paulista (Unesp) e Universidade Federal de Santa Catarina (UFSC).

Estes cursos objetivam, de maneira geral, titular profissionais em mestrado e/ou doutorado, capacitandoos para a pesquisa e, sobretudo, formando uma massa crítica na área de CI que atenda às exigências de preparação de quadros de profissionais aptos à docência em cursos de graduação e pós-graduação na referida área. 
A pós-graduação adquiriu grande importância no sistema de ensino superior brasileiro, tendo passado por notado crescimento nos anos 90 do século XX. Segundo Velloso (2005), até bem pouco tempo, as percepções da comunidade acadêmica sobre o destino profissional de mestres e doutores pautavam-se por observações assistemáticas. Na primeira metade dos anos 90 do século $\mathrm{XX}$, na literatura nacional, desenvolveu-se um debate sobre alternativas de formação pós-graduada. Por isso, vários estudos estão sendo desenvolvidos recentemente para identificar quem são os mestres e doutores titulados, o que faziam antes e o que passaram a fazer após a titulação e que contribuições os cursos aportaram ao seu desempenho profissional e o como eles têm contribuído para o campo científico da ciência da informação.

\section{O Instituto de Ciência da Informação da UFBA e a Pós-graduação}

A Escola de Biblioteconomia e Documentação da Bahia tem suas origens no Curso de Biblioteconomia, criado em 1942. Passou à categoria de Escola, denominada Biblioteconomia e Documentação, em 1954, por força de convênio que a anexou à então Universidade da Bahia. Em 1958 foi integrada à Universidade e em 1968 mudou o nome para Escola de Biblioteconomia e Comunicação, em decorrência da reestruturação da já Universidade Federal da Bahia e da reunião com o Curso de Jornalismo. Em 1987 a Portaria MEC n. 630 criou a Faculdade de Comunicação e fez com que a Escola retomasse seu nome de Escola de Biblioteconomia e Documentação, atualmente Instituto de Ciência da Informação.

Considerando-se que o nome atual não era representativo, recomendou-se sua modificação para Instituto de Ciência da Informação (ICI). Isto decorre de sua universalidade e reconhecimento internacional como área de conhecimento que abrange diversas disciplinas acadêmicas relacionadas com o estudo da informação, incluindo a biblioteconomia, arquivologia e novas profissões, visando ao estudo do fenômeno dos registros do conhecimento, sua produção e uso pela sociedade.

O Programa de Pós-graduação foi iniciado, no ICI, em 1995 mediante convênio com a UnB, com ênfase na área da ciência da informação, e a primeira seleção, com sua própria estrutura, foi realizada em dezembro de 1997 para início do curso no primeiro semestre de 1998. A área de concentração do curso é informação e conhecimento na sociedade contemporânea, integrando duas linhas de pesquisa: informação e conhecimento em ambientes organizacionais e informação e contextos socioeconômicos. Essas linhas de concentração definem os diversos temas sobre os quais podem ser desenvolvidas as dissertações de pós-graduação.

\section{ESTUDO DE EGRESSOS EM CIÊNCIA DA INFORMAÇÃO}

Em relação aos estudos de acompanhamento de egressos, nos diz Souza Júnior (2000, p.14):

O 'acompanhamento de egressos' é uma análise e avaliação de impactos ou de resultados de atividades desenvolvidas. Qualquer que seja seu foco e corte teórico e metodológico, estes são sempre inspirados na crença de que seus resultados, de uma maneira ou de outra, serão úteis na reorientação de políticas e práticas institucionais ou sociais de modo a tornar mais eficiente, mais relevante e mais conseqüente o conjunto dos trabalhos desenvolvidos por uma organização burocrática ou social.

De acordo com Santos (2006), trabalhos sobre egressos foram realizados no âmbito do Ibict. Pode-se citar a pesquisa de Araújo (1982), que analisou a atuação profissional dos egressos do Curso de Mestrado em Ciência da Informação do Ibict, no período de 1970. 1979, envolvendo 121 sujeitos, fazendo um paralelo entre a atuação desses e a atuação profissional de egressos da Inglaterra e dos Estados Unidos. Já a pesquisa de Silva (1982) visou ao estudo do impacto dos cursos de mestrado em CI e de especialização em documentação científica do Ibict sobre a atividade profissional dos egressos.

A pesquisa de Silva (1982) pretendeu analisar a ocupação anterior à realização do curso do Ibict e a atuação profissional posterior à realização do curso, no intuito de verificar o impacto do curso do Ibict na atividade profissional dos egressos. $\mathrm{O}$ estudo utilizou a metodologia de "survey", envolveu uma população de 340 egressos, tendo um retorno de 280 sujeitos correspondendo, assim, a $83 \%$ da população. Os resultados demonstraram que houve certa mudança na atuação profissional, podendo ser creditada ao curso do Ibict.

\section{Egressos do Programa de Pós-graduação da UFBA}

Dada a breve explanação sobre a pós-graduação no Brasil, feito o levantamento de questões históricas e teóricas 
do campo do conhecimento da ciência da informação e feito o registro da história da pós-graduação do Posici/ UFBA, é de suma importância que neste cenário sejam realizados estudos sobre os destinos e as contribuições dos egressos para o fortalecimento desta área do conhecimento.

Para tanto, foi delineado um projeto de pesquisa cujo problema colocado se propôs a investigar a relação existente entre a formação recebida pelos egressos do Programa de Pós-graduação em Ciência da Informação da UFBA (Posici/UFBA) e a contribuição dos mesmos para a área de $\mathrm{CI}$, em termos de desenvolvimento do campo científico e de sua atuação profissional após a titulação.

Diante dessa intenção, estabeleceram-se como objetivos gerais: a) investigar a atuação profissional e a contribuição para o campo científico da ciência da informação por parte dos egressos do Programa de Pós-graduação em Ciência da Informação da UFBA-Posici que defenderam suas dissertações no período de 1998-2006; b) apresentar indicadores que permitam análise de diagnóstico e tendências sobre o desempenho dos cursos, dos próprios titulados e do seu mercado profissional a partir de dados coletados juntos aos egressos da pós-graduação.

Como objetivos específicos: a) caracterizar os egressos; b) identificar as motivações que os levaram à procura da pós-graduação; c) avaliar a qualidade teórica do programa dos cursos; d) avaliar o desenvolvimento da pesquisa para fins de dissertação e o papel do orientador; e) identificar a relação entre a ocupação profissional dos egressos com a área da ciência da informação; f) apreender facilidades / dificuldades para estabelecimento de vínculos entre formação e área de atuação; g) investigar o relacionamento e a contribuição dos egressos do Programa de Pós-graduação em Ciência da Informação por meio de publicações nacionais e internacionais; $h$ ) identificar a relação que os egressos do PPGCI-UFBA mantêm atualmente com a área da ciência da informação; i) analisar os subsídios coletados para o estabelecimento de políticas de formação que possam contribuir com o PPGCI/UFBA; j) avaliar o impacto dos cursos de pósgraduação nas atividades profissionais, no desempenho das atividades acadêmicas de docência e pesquisa.

As hipóteses que nortearam a pesquisa foram assim elaboradas: há pouca contribuição dos egressos de pósgraduação do ICI / UFBA na área de ciência da informação, no que tange ao desenvolvimento do campo científico mediante pesquisas, participação em eventos, fóruns de discussão, publicação de artigos, livros e outras manifestações pertinentes à área; a formação em ciência da informação capacitou os egressos para um olhar diferenciado sobre a importância da informação em nossa sociedade e dentro das organizações, contudo as ocupações profissionais dos egressos continuam centradas na formação inicial.

Foram utilizadas modalidades quantitativas e qualitativas de coleta e análise de dados, na perspectiva de melhor aproximar o objeto, ou seja, o estudo de competências específicas da titulação (conhecimentos), competências profissionais, competências acadêmicas, competências transversais (sistêmicas, pessoais, instrumentais). Tudo isso envolvendo quatro linhas de saberes: saberes do conteúdo; saberes de transferência e transcendência de conteúdo, habilidades e atitudes dos profissionais egressos da pós-graduação; saberes derivados da transposição metodológica de estudo e pesquisa e seu efeito na consolidação dos saberes profissionais nos egressos; saberes sobre métodos e técnicas de construção do conhecimento esperados pelo usuário. Foram utilizados questionários a toda população da pesquisa mestres que defenderam suas dissertações no referido período.

A coleta de dados, em um primeiro momento, foi desenvolvida junto à secretaria da PPGCI / UFBA, visando a identificar os egressos e os respectivos contatos. A partir daí foram utilizadas estratégias como contatos pessoais, busca do currículo pela Plataforma Lattes do CNPq (http://lattes.cnpq.br), em que estão expostos os principais pontos da vida acadêmica, como participação em bancas, orientações de trabalhos, publicação de livros, artigos e outros, instituição a que está vinculado, grau acadêmico e outros dados.

Os instrumentos de pesquisa utilizados para a coleta de dados foram questionário e entrevista. $\mathrm{O}$ questionário para os egressos, composto de questões fechadas e abertas, abordou: perfil, formação, ocupação profissional, docência e desenvolvimento do campo executivo, além de pontos de vista de caráter pessoal.

Realizou-se um estudo documental a fim de verificar a existência de publicação, por parte dos egressos, de artigos nos periódicos da área da ciência da informação do Brasil. Para tal, utilizou-se como parâmetro de qualidade dos periódicos a listagem QUALIS e selecionaram-se alguns periódicos. Outro levantamento a ser procedido foi em relação à publicação de trabalhos por parte dos egressos no Encontro Nacional de Pesquisa em Ciência da Informação (Enancib). 


\section{Egressos do Posici/UFBA}

O total de alunos da Pós-Graduação do Posici/UFBA, durante o período de 1998 a 2006, foi de 52. Verificouse que a principal característica foi a diversidade de formação acadêmica que trazem quando ingressam na pós-graduação, enfatizando a sua natureza interdisciplinar, tema de discussão em vários trabalhos acadêmicos da área da ciência da informação, conforme tabela 1 .

A pós-graduação em ciência da informação no seu início se caracterizou por ter maior número de bibliotecários entre seus alunos. Pressupõe-se ter sido a oportunidade que a maioria dos bibliotecários vislumbrou como oportunidade para atualizar seus estudos sem deslocar-se para outros estados do Brasil. Contudo, nos anos de 2002 a 2004, o número de alunos de outras áreas do conhecimento ultrapassou o número de bibliotecários, registrando-se, desse modo, a tendência da ciência da informação em qualificar não só bibliotecários, mas também outros segmentos que trabalham com a informação; observe-se que em 2003 há equilíbrio entre as diversas áreas e a área de biblioteconomia.

A faixa etária dos egressos está centrada em pessoas acima de 30 anos (tabela 2). Infere-se que isso ocorra por exigência do mercado, que necessita de profissionais cada vez mais capacitados para atender ao novo perfil das instituições que trabalham com informação e conhecimento.

\section{TABELA 1}

Área de graduação

\begin{tabular}{|c|c|c|c|c|c|c|c|c|c|}
\hline Área de Graduação & 1998 & 2002 & 2003 & 2004 & 2005 & 2006 & 2007 & Total & $\%$ \\
\hline Administração & & 01 & 01 & 01 & & & & 03 & 4,0 \\
\hline Analista de Sistema & & 01 & & & & & & 01 & 1,3 \\
\hline Arquitetura & & & 01 & & & & & 01 & 1,3 \\
\hline Arquivologia & & & & & & & 01 & 01 & 1,3 \\
\hline Biblioteconomia & 06 & 02 & 04 & 01 & 03 & 05 & 08 & 28 & 36,9 \\
\hline Ciências Contábeis & 01 & & 01 & & & & & 02 & 2,6 \\
\hline Ciências Econômicas & & & & & & & 01 & 01 & 1,3 \\
\hline Ciência da Computação & & & & 01 & & 02 & 01 & 04 & 5,3 \\
\hline Ciências Sociais & & & & 01 & & & & 01 & 1,3 \\
\hline Comunicação & & & & 01 & 01 & 01 & & 03 & 4,0 \\
\hline Comunicação Social & & & & & 03 & & & 03 & 4,0 \\
\hline Desenho Industrial & & & & & 01 & & & 01 & 1,3 \\
\hline Direito & & & 01 & & 02 & & & 03 & 4,0 \\
\hline Eng. Civil & & 01 & 01 & 01 & & & & 03 & 4,0 \\
\hline Eng. da Computação & & & & & & 01 & & 01 & 1,3 \\
\hline Eng. Elétrica & & 01 & & 01 & & & & 02 & 2,6 \\
\hline Eng. Eletrônica & & & & & & 01 & & 01 & 1,3 \\
\hline Eng. Mecânica & 01 & & & & & 01 & 01 & 03 & 4,0 \\
\hline Eng. Química & & 01 & & & & & & 01 & 1,3 \\
\hline Informática & & & & 01 & & & & 01 & 1,3 \\
\hline Lic. Matemática & & 01 & & & & & & 01 & 1,3 \\
\hline Medicina & & & & & 01 & 01 & & 02 & 2,6 \\
\hline Museologia & 01 & & & & & & & 01 & 1,3 \\
\hline Música & & & & 01 & & & & 01 & 2,6 \\
\hline Pedagogia & & 01 & 01 & & & & & 02 & 2,6 \\
\hline Process. de Dados & & & 01 & & & 01 & & 02 & 2,6 \\
\hline Secretariado Executivo & & 01 & & & & & 01 & 02 & 2,6 \\
\hline TOTAL & 09 & 10 & 11 & 09 & 11 & 13 & 12 & 76 & 100 \\
\hline
\end{tabular}


TABELA 2

Faixa etária dos egressos

\begin{tabular}{c|c|c|c|c|c|c|c|c|c}
\hline \multicolumn{1}{c|}{ IDADE } & 1998 & 2002 & 2003 & 2004 & 2005 & 2006 & 2007 & Total & $\%$ \\
\hline Menos de 32 anos & 01 & 03 & 04 & 02 & 02 & 02 & 03 & 17 & 22,3 \\
\hline De 32 a 39 anos & 03 & 02 & 02 & 04 & 03 & 04 & 03 & 21 & 27,7 \\
\hline De 40 a 47 anos & 03 & - & 03 & - & - & 03 & 05 & 14 & 18,4 \\
\hline De 48 a 55 anos & - & 05 & 02 & - & 05 & 02 & 02 & 16 & 21,1 \\
\hline Mais de 55 anos & 02 & - & - & 03 & 01 & 02 & - & 08 & 10,5 \\
\hline \multicolumn{1}{c}{ TOTAL } & 09 & 10 & 11 & 09 & 11 & 13 & 13 & 76 & 100 \\
\hline
\end{tabular}

A maioria dos profissionais que cursam o Posici/UFBA está inserida no mercado de trabalho, o que leva a registrar o baixo número de bolsistas no curso, variando em média de duas a três bolsas por ano (Fapesb e Capes).

Quanto ao tempo decorrido para a titulação (tabela 3), há tendência de ultrapassar o limite de tempo regulamentar permitido. Deduz-se que, no primeiro ano, os alunos se dediquem a cursar as disciplinas oferecidas pelo curso, deixando pouco tempo para a fase de coleta e análise de dados e elaboração da dissertação.

As linhas de pesquisa dos projetos dos alunos do Posici/ UFBA mudaram conforme os ajustes do projeto do Programa de Pós-graduação, justificando-se pelas mudanças ocorridas nas possíveis temáticas que se integram aos estudos da ciência da informação (tabela 4).

Nota-se predominância do sexo feminino, o que pode ser associado à predominância também do sexo feminino nos cursos de biblioteconomia, já que uma boa parte dos sujeitos que concorrem à seleção do Programa de Pós-Graduação em Ciência da Informação (Posici/UFBA) advém dessa área de graduação (tabela 5). Não podemos ignorar que ainda hoje as relações entre os gêneros permeiam qualquer interação social e são baseadas em desigualdades. As tecnologias de comunicação e informação (TICs) de última geração tiveram impacto em todo o globo e transformaram a informação em um dos bens mais valorizados e procurados do mercado, tornando-se condição básica e crescente para o desenvolvimento econômico, político, social e cultural de todo e qualquer indivíduo, independentemente de sexo, idade e nacionalidade. Neste sentido, as tecnologias de informação e comunicação são vistas como meio pelo qual grupos de mulheres conseguem acesso a dados e informações e, ainda, como recurso para tornar todo tipo de informação disponível a outras mulheres (ABATH; IRELAND, 2002). Segundo Sampaio e Aragon (2002), as novas tecnologias, em especial a web, introduzem possibilidades teóricas para as mulheres e
TABELA 3

Tempo decorrido para a titulação

\begin{tabular}{|c|c|c|c|}
\hline \multirow{2}{*}{$\begin{array}{l}\text { ANO DE } \\
\text { INGRESSO }\end{array}$} & \multirow{2}{*}{$\begin{array}{l}\text { ANO DE } \\
\text { DEFESA }\end{array}$} & \multicolumn{2}{|c|}{ QUANTIDADE } \\
\hline & & Abs. & $\%$ \\
\hline \multirow{3}{*}{1998} & 1999 & 01 & 11,1 \\
\hline & 2001 & 01 & 11,1 \\
\hline & 2002 & 07 & 77,8 \\
\hline \multicolumn{2}{|r|}{ Total } & 09 & 100 \\
\hline \multirow[t]{3}{*}{2002} & 2004 & 05 & 50,0 \\
\hline & 2005 & 04 & 40,0 \\
\hline & 2006 & 01 & 10,0 \\
\hline \multicolumn{2}{|r|}{ Total } & 10 & 100 \\
\hline \multirow{2}{*}{2003} & 2005 & 07 & 63,6 \\
\hline & 2006 & 04 & 36,4 \\
\hline \multicolumn{2}{|r|}{ Total } & 11 & 100 \\
\hline \multirow{2}{*}{2004} & 2005 & 01 & 11,1 \\
\hline & 2006 & 08 & 88,9 \\
\hline \multicolumn{2}{|r|}{ Total } & 09 & 100 \\
\hline \multirow{3}{*}{2005} & 2006 & 01 & 9,0 \\
\hline & 2007 & 05 & 45,5 \\
\hline & & $05^{*}$ & 45,5 \\
\hline & Total & 11 & 100 \\
\hline
\end{tabular}

*Esses cinco aguardam defesa.

\section{TABELA 4}

Linha de pesquisa por período de ingresso

\begin{tabular}{|c|c|c|c|}
\hline \multirow{2}{*}{ ANO } & \multirow{2}{*}{ LINHA DE PESQUISA } & \multicolumn{2}{|c|}{ QUANTIDADE } \\
\hline & & Abs. & $\%$ \\
\hline \multirow{3}{*}{1998} & Tecnologia, Redes e Sistemas de Informação & 01 & 11,2 \\
\hline & Informação para a Indústria e Negócios & 04 & 44,4 \\
\hline & Política e Gestão da Inform ação & 04 & 44,4 \\
\hline \multirow{3}{*}{2002} & Total & 09 & 100 \\
\hline & Informação e Contextos Socioeconômicos & 05 & 50,0 \\
\hline & Estrutura e Linguagens da Informação & 05 & 50,0 \\
\hline \multirow{3}{*}{2003} & Total & 10 & 100 \\
\hline & Informação e Contextos Socioeconômicos & 09 & 81,8 \\
\hline & Estruturas e Linguagens da Informação & 02 & 18,2 \\
\hline \multirow{3}{*}{2004} & 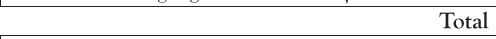 & 11 & 100 \\
\hline & Informação e Contextos Socioeconômicos & 04 & 44,4 \\
\hline & Teoria e Gestão do Conhecimento & 05 & 55,6 \\
\hline \multirow{3}{*}{2005} & Total & 09 & 100 \\
\hline & Informação e Contextos Socioeconômicos & 06 & 54,5 \\
\hline & Teoria e Gestão do Conhecimento & 05 & 45,5 \\
\hline \multirow{3}{*}{2006} & Total & 11 & 100 \\
\hline & Informação e Contextos Socioecon ômicos & 09 & 69,2 \\
\hline & Informação em Ambientes Organizacionais & 04 & 30,8 \\
\hline \multirow{3}{*}{2007} & Total & 13 & 100 \\
\hline & Informação e Contextos Socioeconômicos & 09 & 69,2 \\
\hline & Informação em Ambientes Organizacionais & 04 & 30,8 \\
\hline & Total & 13 & 100 \\
\hline
\end{tabular}


benefícios relacionados ao acesso, os quais expandem as possibilidades da expressão feminina.

Do universo de 52, referente ao período de 1998-2006, somente 20 egressos se dispuseram a responder aos instrumentos de coleta de dados. Assim, em relação às expectativas que os egressos traziam sobre o Curso de Pós-Graduação do ICI/UFBA, 35\% relacionavam-se com a necessidade de aperfeiçoamento para o exercício da docência; 25\% com o desenvolvimento de habilidades para a pesquisa científica; $15 \%$ com o aprofundamento de conhecimentos sobre a CI. Infere-se, portanto, que a procura pela pós-graduação dá-se em nome da exigência do mercado, pois, para se continuar atuando, necessitase ir além da graduação e que sempre esteja se qualificando.

De acordo com os dados levantados sobre as contribuições do curso nas atividades profissionais, as respostas evidenciaram a necessidade de adquirir a compreensão e aumento do conhecimento em relação à pesquisa, à prática da docência, além de maior compreensão sobre o fenômeno "informação", a exemplo de: "Melhoria dos conhecimentos em metodologia da pesquisa"; "Ampliação de conhecimentos no campo da ciência da informação"; "Novo olhar sobre as conexões da biblioteconomia e arquivologia com a ciência da informação"; "Adicional de qualificação no trabalho"; "Iniciação na docência na área de informação".

Diante da questão "após a titulação, houve alguma mudança nas atividades profissionais desempenhadas? As mudanças foram significativas? Algumas das respostas registradas foram: "Maior produção e disseminação do conhecimento na área de atuação"; "Maior desenvoltura nas palestras sobre serviços da biblioteca"; "Aulas e didáticas mais ricas de fundamentos epistemológicos"; "Plataforma para o doutorado pleno no exterior"; "Adoção por parte da empresa de projetos baseados na dissertação"; "Maior segurança nas consultorias".

Egressos que exercem docência (60\%) declararam que o curso de pós-graduação contribuiu da seguinte maneira: "melhoria do conhecimento em metodologia da pesquisa"; "melhor qualificação profissional docente"; "melhor qualidade na orientação de monografias da graduação e especialização"; "revisão e otimização do conteúdo programático das disciplinas ministradas"; "contribuição na formação como pesquisadora, porém falta conteúdo pedagógico e didático”.
TABELA 5

Distribuição por sexo

\begin{tabular}{c|c|r|c|r}
\hline \multirow{2}{*}{ ANO } & \multicolumn{4}{|c}{ SEXO } \\
\cline { 2 - 5 } & \multicolumn{2}{|c|}{ Feminino } & \multicolumn{2}{c}{ Masculino } \\
\cline { 2 - 5 } & Abs. & \multicolumn{1}{c}{$\%$} & \multicolumn{1}{c}{ Abs. } & \multicolumn{1}{c}{$\%$} \\
\hline 1998 & 07 & 14,6 & 02 & 7,1 \\
\hline 2002 & 07 & 14,6 & 03 & 10,7 \\
\hline 2003 & 05 & 10,5 & 06 & 21,4 \\
\hline 2004 & 04 & 8,3 & 05 & 17,9 \\
\hline 2005 & 09 & 18,7 & 02 & 7,1 \\
\hline 2006 & 07 & 14,6 & 05 & 17,9 \\
\hline 2007 & 09 & 18,7 & 05 & 17,9 \\
\hline TOTAL & 48 & 100 & 28 & 100 \\
\hline
\end{tabular}

A partir das afirmações dos egressos sobre docência, cabe refletir se o curso de pós-graduação em CI da UFBA é o locus de formação pedagógica? Há disciplinas que subsidiem o trabalho pedagógico de forma a tornar os alunos aptos a reelaborar conteúdos e metodologias de construção do conhecimento? Atualmente, a formação pedagógica é destacada e, de certa forma, valorizada pela necessidade de melhoria do processo de inovação pedagógica, a fim de atender aos interesses dos alunos e às exigências do mundo do trabalho.

Metodologia Científica foi citada por $60 \%$ dos egressos como a disciplina que mais contribuiu para o desempenho profissional, porém as respostas dadas à questão "quais disciplinas não contribuíram com o desempenho profissional" foram evasivas (35\%), ou não foi respondida (25\%) e o restante do percentual foi distribuído na citação de outras disciplinas, a exemplo de: Tecnologia da Informação, Economia da Informação, Informação e Sociedade Global. Como exemplo de respostas evasivas, teve-se: "Todas contribuíram de certa maneira"; "Todas contribuíram"; "De certa forma todas contribuíram"; "Não aplicável”.

Foi perguntado até que ponto os egressos tinham algum tipo de vínculo com a ciência da informação antes de ingressarem no curso, e verificou-se que, como a maioria dos entrevistados era da área de biblioteconomia, as respostas foram positivas, a exemplo de "Leitura para entender a conexão biblioteconomia, arquivologia e ciência da informação"; "Desenvolvimento de sistemas para a web”; "Direção de biblioteca universitária; participação no Proler"; "Participação em eventos na área como ministrante de cursos e palestras"; "Planejamento do tratamento da informação no serviço publico"; "Projeto de inclusão digital e eficiência do poder público"; "Busca e recuperação em bases de dados bibliográficas"; 
"Participação na comissão editorial de periódicos acadêmicos"; "Oficina de normalização de textos acadêmicos"; "Processamento técnico de material bibliográfico”.

Também foram coletados e analisados dados sobre a contribuição dos egressos para a área da ciência da informação, seja pela prática profissional, seja pela colaboração de projetos, como também de artigos publicados em periódicos (individual ou em parceria), que tenham visibilidade na área $\mathrm{da} \mathrm{CI}$.

Quanto à contribuição do Curso de Pós-Graduação do Posici na prática profissional, os egressos registraram que conhecimento da área fortaleceu "a investigação científica e a produção do conhecimento"; "o trabalho de estímulo à leitura entre alunos de graduação para discutir conceitos, fronteiras e conexões da ciência da informação com a biblioteconomia e a arquivologia, para evitar equívocos conceituais nos discursos e na prática profissional”; “a orientação de pesquisa para pósgraduandos"; "o processo normalização e pesquisa em periódicos"; "o desenvolvimento de sistemas para a web"; "as ações de coordenação de um curso de graduação em CI"; "as ações de coordenação de uma revista acadêmica (O SEER)"; "a coordenação de pesquisa de discentes do curso de CI na área de bibliotecas públicas"; "a busca e recuperação da informação em bases de dados bibliográfica"; "o processamento técnico de material bibliográfico"; “a implementação de projetos visando à maximização da informação no processo de fiscalização"; "a docência com conhecimento mais sólido sobre pesquisa”.

O egresso da pós-graduação registrou que os conhecimentos teórico-metodológico advindos do curso possibilitaram a produção e transferência de conhecimentos em atuações profissionais. Isso é confirmado quando eles declararam que houve um fortalecimento na prática profissional no que tange à elaboração de projetos. Após o curso, o panorama da produção de projetos registrados pelos egressos foi o seguinte: "Autonomia no uso da informação na Internet"; "Biblioteca cidadã, momentos literários na biblioteca"; "Pesquisa sobre o número de bibliotecas escolares na rede de ensino público em Vitória da Conquista"; "Projeto gestão do Conhecimento no Cenário Brasileiro"; "Co-autoria do Projeto Bibliotecas sem Fronteiras UFBA"; "Membro do Grupo de Pesquisa Disseminação e Uso da Informação"; "Projeto de Cenários de Fraudes"; "Sistema Integrado de Informação de Fraudes Fiscais"; "Vigilância na Rede Consubstanciados na Metodologia da Inteligência Competitiva"; "Infra-estrutura de Geodados para a Prefeitura Municipal de Salvador"; "Disponibilização de Dados Geográficos no Google Earth"; "Portal Corporativo do Instituto do Recôncavo de Tecnologia"; "Gestão da Informação de Saúde dos Trabalhadores no Contexto da Inteligência Organizacional”.

Ao analisar as ementas das disciplinas oferecidas no Curso de Pós-Graduação em CI da UFBA, infere-se que o aluno apreende competências e habilidades em subáreas que compõem o diversificado espectro de abrangência da CI, o que identifica a intenção dos objetivos do curso quando oferece amplo leque de possibilidades aos seus alunos para auxiliá-los nas atividades de pesquisa e na geração de conhecimento na $\mathrm{CI}$, apesar de que alguns estudiosos registram que a dispersão de disciplinas dificulta a formação de identidade da área. Justificam-se, portanto, os cursos de pós-graduação como acionadores do processo de formação acadêmica e profissional continuada, e de perspectivas para a compreensão dos fenômenos sociais que envolvam a pluralidade, a heterogeneidade e a complexidade.

No que tange à participação em eventos durante o curso, o Encontro Nacional de Ciência da Informação (Cinform), realizado em Salvador, foi o mais citado (50\%). Outros eventos contemplados com uma ou duas respostas constantes foram os seguintes: Encontro Nacional de Pesquisa em Ciência da Informação (Enancib), realizado na capital baiana em 2007, Seminário Nacional de Bibliotecas Universitárias (SNBU), realizado em Salvador em 2006, Congresso da Sociedade Brasileira de Gestão do Conhecimento, Congresso de Inteligência Competitiva, Congresso Brasileiro de Arquivologia, Congresso de Arquivologia e de Gestão do Conhecimento, Seminário Sociedade da Informação e a Universalização de Acesso. Apenas uma pessoa respondeu que apresentou trabalho em um dos eventos.

Quanto à contribuição dos egressos para a divulgação e o desenvolvimento do campo científico da área da $\mathrm{CI}$, constatou-se que, dos 20 respondentes, 50\% não publicaram nenhum artigo, 50\% publicaram em periódicos que fazem parte da lista QUALIS. As revistas citadas foram as seguintes: Information Research, Bahia Análise e Dados, BIBLIOS Revista Eletrónica de Ciencias de la Información, Ciência da Informação, DataGramaZero, EDUCS, Eptic On-Line, Informação $\mathcal{E}$ Sociedade, Revista Biblionline, Revista Juridica da SJBA, Revista Ponto de Acesso, Revista Tectura, TECBAHIA Revista Baiana de Tecnologia. 
Considerando a proposta da pesquisa - investigar a relação existente entre a formação recebida pelos egressos do Programa de Pós-graduação em Ciência da Informação da UFBA (POSICI/UFBA) e a contribuição dos mesmos para a área de $\mathrm{CI}$, em termos de desenvolvimento do campo científico e de sua atuação profissional após a titulação -, considera-se que os dados obtidos podem ser analisados sob a ótica de três dimensões: individual, que enfatiza as diferenças individuais quanto à apreensão e transferência do conhecimento e os diferentes paradigmas em que foram formados; coletiva, que reconhece que cada profissional, na essência do ser e fazer, é semelhante a outros profissionais com os quais compartilham experiências; universal, que permite refletir que cada profissional guarda semelhanças com todos os de sua mesma geração. Ou seja, cada egresso consultado contribuiu de acordo com o seu compromisso e necessidade profissional e acadêmica, não havendo propriamente uma contribuição universal teórica que ampliasse o campo científico da área, considerando-se os diferentes paradigmas que vêm passando o campo da $\mathrm{CI}$, quanto ao caráter epistemológico, conceitual e metodológico.

\section{CONCLUSÃO}

De acordo com estudos da área da CI, a grande diversidade de formação do egresso contribui para a interdisciplinaridade da CI. Contudo, ao se analisarem as contribuições, constata-se que os graduados em biblioteconomia foram os que mais fortaleceram a área, com a publicação de artigos e participação de eventos, embora ainda seja uma participação pouco consistente para dar visibilidade à CI.

Ficou claro que os egressos procuraram o curso do PPGCI/UFBA como uma forma de aperfeiçoamento profissional e de desenvolver habilidades para a pesquisa. Constatou-se que $40 \%$ dos egressos já exerciam a docência e 20\% deles passaram a exercer após a titulação. Esta assertiva se confirma quando foram questionados sobre as expectativas que eles tinham em relação ao curso. Trinta e cinco por cento deles responderam que necessitavam se capacitar para exercer a docência, e só $25 \%$ desejavam desenvolver habilidades para a pesquisa científica.

As atividades exercidas antes e após o ingresso na pósgraduação continuaram as mesmas, acrescidas do exercício da docência para uma parte dos egressos. Ao se analisarem os resultados desta pesquisa, no que diz respeito às atividades de pesquisa e publicações, fica a questão: quem é o profissional da informação? Seriam todos aqueles que lidam com a informação, seja ele bibliotecário, jornalista e outros que lidam com a tecnologia da informação? Le Coadic (1996) apresenta a seguinte classificação para os profissionais da informação:

a) especialistas da informação - categoria ampla, inclui pessoas que não trabalham, em geral, no ambiente da biblioteca tradicional (...). Estão mais voltadas para a análise, comunicação e uso da informação, do que para o armazenamento e a conservação das coleções de documentos e objetos (...). São denominados como analistas da informação, gerentes da informação, planejadores de sistemas de informação (p.107-108);

b) empresários da informação - grupo constituído por profissionais da informação que criam empresas de fabricação e venda de produtos ou serviços de informação. (...) $\bigcirc$ produto da informação pode ser um banco de informações especializadas, um programa de computador, publicações (índices, catálogos, etc.) (p.108);

c) cientistas da informação - é a comunidade científica formada por pesquisadores e docentes que pesquisam e ensinam na área de ciência da informação. Trabalham em universidades, centros de pesquisa ou para grandes empresas que implantaram programas de pesquisa, visando a estudar as propriedades da informação e desenvolver novos sistemas e produtos de informação (p. 108).

O IV Plano Nacional de Pós-Graduação (PNPG) para o período de 2005-2010 reconhece que um dos desafios a serem enfrentados é a formação de profissionais com perfis diferenciados, no intuito de responder à dinâmica tanto do campo acadêmico quanto do não acadêmico. Duas das vertentes estabelecidas para a expansão do sistema de pós-graduação de algum modo vinculam-se a esse desafio: a especialização para o trabalho no setor público e no setor privado, e a formação de pesquisadores e técnicos para empresas, tanto públicas quanto privadas (VELLOSO, 2005).

Diante do papel dos cursos de pós-graduação, pode-se considerar que:

- em meio a todos os benefícios que o sistema de educação superior pode gerar para o processo de inovação - seja para o setor produtivo, seja para a sociedade como um todo - , a formação de recursos humanos parece ser o mais importante; 
- o sistema de ensino superior desempenha papel proeminente nos sistemas de inovação, servindo a uma série de funções. De todas elas a formação de recursos humanos qualificados é considerada como sendo a mais importante;

- é papel dos cursos de pós-graduação formar pessoas capazes de transformar conhecimento científico em atuações profissionais para a sociedade. Esta perspectiva é reforçada pela opinião de González de Gómez (2003), que diz que a pós-graduação pode caracterizar-se pela formação de competências muito complexas e específicas e a participação na produção de conhecimentos científicos. A pós-graduação entrecruza a formação de recursos humanas - estes relacionados com o universo do trabalho - e na outra vertente a geração de conhecimentos relacionados com os espaços da pesquisa científico-tecnológica;

- quando se forma um cientista e este atua como professor de nível superior, ele está formando outros profissionais que irão atuar tanto na graduação quanto na pós-graduação, beneficiando a sociedade por meio da produção do conhecimento. "A responsabilidade específica dos mestrados e doutorados é desenvolver capacidades nas pessoas para produzirem conhecimento e torná-lo acessível à sociedade." (BOTOMÉ; KUBO, 2002, p.92);

- a pós-graduação contribui com o aprendizado para que se possam construir conhecimentos novos, e, de posse desse aprendizado, os egressos devem estar aptos a fazer parte do corpo de pesquisadores dos institutos de pesquisa e do corpo docente de nível superior de diversas universidades ou outras instituições, transformando conhecimento novo em bens e serviços para a sociedade;

- para que o sistema do ensino superior possa contribuir com a formação de pesquisadores para o processo de inovação, é necessário que exista um sistema de pósgraduação operante e sustentável;

- a formação de novos pesquisadores só pode ter impacto positivo para os processos de inovação e para o desenvolvimento, se houver qualidade nos cursos oferecidos.
Como ciência, a CI é um campo científico em construção e não se pode afirmar, consensualmente, qual o seu objeto e a extensão do seu campo de atividades, mas sabe-se que o principal objeto é a informação. Existem três pontos principais questionários em função deste objeto: a) o ajuste de ferramentas tecnológicas, além de estratégias para tornar mais acessível o crescente conteúdo de conhecimento e informação; b) como fornecer informações relevantes para indivíduos, grupos e organizações envolvidas com a ciência e tecnologia, já que a informação é um importante insumo para se atingir e desenvolver essas áreas e outros campos do conhecimento; como descrever sucintamente a informação de maneira inteligível, que satisfaça as necessidades específicas de cada indivíduo (SARACEVIC, 1996, p. 43).

Para que o campo científico da CI avance, é preciso que a comunidade científica também se fortaleça por meio da produtividade e comprometimento com o desenvolvimento da área, direcionando esforços no aprofundamento das pesquisas que venham a contribuir para a questão epistemológica da CI.

Os resultados aqui apresentados são produto de uma primeira fase dos estudos de egressos, resultantes de uma defesa de dissertação de mestrado, além de um estudo de iniciação científica. O estudo continua a ser desenvolvido, buscando aprofundar aspectos não respondidos nesta primeira fase, para consolidar a metodologia inicialmente adotada, no sentido de contribuir efetivamente com o estudo de competências específicas da titulação (conhecimentos), competências profissionais, competências acadêmicas, competências transversais (sistêmicas, pessoais, instrumentais). Tudo isso envolvendo quatro linhas de saberes: saberes do conteúdo; saberes de transferência e transcendência de conteúdo, habilidades e atitudes dos profissionais egressos da pós-graduação; saberes derivados da transposição metodológica de estudo e pesquisa e seu efeito na consolidação dos saberes profissionais nos egressos; saberes sobre métodos e técnicas de construção do conhecimento esperados pelo usuário.

Artigo submetido em 03/11/2008 e aceito em 26/12/2008. 

por parte dos egressos do PPGCI (ICI/UFBA)

\section{REFERÊNCIAS}

ABATH, Rachel Jofilly; IRELAND, Timothy. A tecnologia da informação e comunicação e o empoderamento da mulher. In: AQUINO, M. A. (Org.). O campo da ciência da informação: gênese, conexões e especificidade. João Pessoa: Universitária/UFPB, 2002.

ABOTT, Andrew. The system of professions: an essay on the division of expert labor. Chicago: The University of Chicago Press, 1998.

BAPTISTA, S. G.; MUELLER, S. P. M. (Org.). Profissional da informação: espaço de trabalho. 1. ed. Brasília: Thesaurus, 2004. 241 p.

BARRetO, Aldo de Albuquerque; MIRANDA, Antonio. Pesquisa em ciência da informação no Brasil: síntese e perspectiva. Revista de Biblioteconomia de Brasília, Brasília, v. 23-24, n. 3, p. 277-292, 2000.

BOTOMÉ, Silvio Paulo; KUBO, Olga Mitsue. Responsabilidade social dos programas de pós-graduação e formação de novos cientistas e professores de nível superior. Interação em Psicologia, v. 6, n. 1, p. 81 $110,2002$.

BOURDIEU, Pierre. O poder simbólico. 9. ed. Rio de Janeiro: Bertrand Brasil, 2006. $311 \mathrm{p}$.

COMISSÃO DO CONVENIO CNPQ/IBICT-UFRJ/ECO. A pósgraduação em ciência da informação na UFRJ. Ciência da Informação, Brasília, v. 16, n. 2, p. 113-124, jul./dez. 1987.

CUNHA, Miriam Vieira da; SOUZA, Francisco das Chagas (Org.). Comunicação, gestão e profissão: abordagens para o estudo da ciência da informação. Belo Horizonte: Autentica, 2006. 175 p.

DUBAR, Claude. A socialização: construção das identidades sociais e profissionais. Tradução Andreia Stahel M. da Silva. São Paulo: Martins Fontes, 2005.

FREIDSON, Eliot. Renascimento do profissionalismo: teoria, profecia e política. Tradução de Celso Mauro Paciornik. São Paulo: Edusp, 1988. 280 p. (Coleção Clássicos, n. 12).

GATTI, Bernadete Angelina. Reflexão sobre os desafios da pósgraduação: novas perspectivas sociais, conhecimento e poder. Revista Brasileira de Educação. São Paulo, n. 18, p. 108-116, set./nov. 2001.

Ibict. Ciência da Informação, Brasília, v. 24, n. 1, p. 31-35, jan./abril 1995.

LANCASTER, Frederick Wilfrid. Ameaça ou oportunidade?: o futuro dos serviços de biblioteca à luz das inovações tecnológicas. Revista da Escola de Biblioteconomia da UFMG, Belo Horizonte, v. 23, n. 1, p. $7-$ 27, jan./jun. 1994.
LÊ COADIC, Yves-François. A ciência da informação. Brasília, DF: Briquet de Lemos, 1996. 119 p.

MCGARRY, Kevin. O contexto dinâmico da informação: uma análise introdutória. Tradução Helena Vilar de Lemos. Brasília: Briquet de Lemos, 1999.

MIRANDA, Ana Claudia Carvalho; SOlinO, Antonia da Silva. Educação continuada e mercado de trabalho: um estudo sobre bibliotecários do estado do Rio Grande do Norte. Perspectivas em Ciência da Informação, v. 11, n. 3, p. 383-397, set./dez. 2006.

MIRANDA, Antonio L. C. A profissionalização da ciência da informação no marco da globalização: paradigmas e propostas. In: LUBISCO, Nídia M. L.; BRANDÃO, Lídia M. B. (Org.). Informação e informática. Salvador: EDUFBA, 2000. p. 65-80.

SAMPAIO, Anna; ARAGON, Janni. Feminismos filtrados: cibersexo, comércio eletrônico e a construção do corpo da mulher no ciberespaço. In: EISENBERG, J.; CEPIK, M. (Org.). Internet e politica: teoria e prática da democracia eletrônica. Belo Horizonte: UFMG, 2002.

SANTOS, Joéfisson Saldanha dos. Atuação profissional e a participação no desenvolvimento do campo científico em ciência da informação: estudo dos egressos do programa de pós-graduação em ciência da informação da UFMG: 1992-2205. Perspectiva Ciência da Informação, Belo Horizonte, v. 11, n. 2, p. 282-287, maio/ago. 2006.

SARACEVIC, Tefko. Ciência da Informação: origem, evolução e relações. Perspectiva em Ciência da Informação, Belo Horizonte, v. 1, n. 1, p. 41-62, jan./jun. 1996. Disponivel em: <http://www.eci.ufmg.br/ pcionline $/$ viewarticle. $p h p ?$ id $=5$ \&layout $=$ abstract $>$. Acesso: 11 set. 2008.

; GOMES, Hagar Espanha; BRAGA, Gilda Maria. Tecnologia da informação, sistemas de informação e informação como utilidade pública. Ciência da informação, Rio de Janeiro, v. 3, n. 1, p. 57-67, 1974.

SILVA, Gilda Olinto do Vale. O impacto dos cursos do IBICT sobre a atividade profissional dos egressos. Ciência da Informação, Brasília, v. 11, n. 2, p. 3-12, 1982.

SOUZA JUNIOR, Hormindo Pereira de. Acompanhamento de egressos. In: MACHADO, Lucilia Regina de Souza; FIDALGO, Fernando Selmar. (Org.). Dicionário de educação profissional. Belo Horizonte: UFMG, 2000. V. 1, p. 13-14.

VELLOSO, Jacques. (Org.). A pós-graduação no Brasil: formação e trabalho de mestres e doutores no país. 2. ed. Brasília: Universidade de Brasília, 2005. V. 1. 